\title{
Role of age and sex in short-term and long term mortality after a first $\mathrm{Q}$ wave myocardial infarction
}

\author{
J Marrugat, M Gil, R Masiá, J Sala, R Elosua, J M Antó, and the REGICOR Investigators
}

Unitat de Lipids $i$ Epidemiologia Cardiovascular, Institut Municipal d'Investigació Mèdica (IMIM), Barcelona,

Spain

J Marrugat

M Gil

R Elosua

Servei de Cardiologia i Unitat Coronària, Hospital Universitari

Dr Josep Trueta Gerona, Spain

R Masiá

J Sala

Unitat de Recerca

Respiratoria i

Ambiental, Institut Municipal

d'Investigació Mèdica (IMIM), Barcelona,

Spain

J M Antó

Correspondence to: Dr Marrugat, Unitat de Lipids i Epidemiologia Cardiovascular, Institu Municipal d'Investigació Mèdica (IMIM), Carrer Dr Aiguader 80,

08003-Barcelona, Spain (jaume@imim.es)

Accepted for publication 21 February 2001

\begin{abstract}
Study objective-The objective of this study was to analyse whether the risk of death within 28 days and three years after a first $Q$ wave myocardial infarction was higher in hospitalised women than in men.

Design-Follow up study.

Patients and setting-All consecutive first $Q$ wave myocardial infarction patients aged 25 to 74 years (447 women and 2322 men) admitted to a tertiary hospital in Gerona, Spain, from 1978 to 1997 were registered and followed up for three years. Main results-Women were older, presented more comorbidity and developed more severe myocardial infarctions than men. A significant interaction was found between sex and age. Women aged 65-74 had higher early mortality risk than men of the same age (OR 1.62; 95\% CI 1.01, 2.66) after adjusting for age, comorbidity and acute complications including heart failure. Women under 65 tended to be at lower risk of early mortality than men $(0.45$ (95\% CI $0.19,1.04)$. Three year mortality of 28 day survivors did not differ between sexes.

Conclusions-These data support the idea that the higher 28 day mortality in hospitalised women with a first $Q$ wave myocardial infarction is mainly attributable to the large number of patients aged 65 to 74 years in whom the risk is higher than that in men. Women under 65 with myocardial infarction do not seem to be a special group of risk.
\end{abstract}

(F Epidemiol Community Health 2001;55:487-493)

Women hospitalised with an acute myocardial infarction (AMI) have higher short-term mortality rates than men. ${ }^{1}$ Such a difference is mostly explained by the greater age of women at the time of myocardial infarction. ${ }^{2}$ Other contributing factors are the increased prevalence of cardiovascular risk factors or comorbidity in women, a tendency toward the underuse of diagnostic procedures or therapeutic interventions in women compared with men. ${ }^{2}$ Some studies have, however, reported a significantly higher mortality in women after adjustment for some or all of these factors. ${ }^{3-8}$ Suggestions as to mechanisms that may be implicated in this excess risk for women have been speculative and remain unclear. $^{910}$ A candidate factor is the higher frequency in women of clinical manifestations of left ventricular dysfunction (acute pulmonary oedema or cardiogenic shock) during the acute phase. $^{26}$
Nevertheless, some studies have reported an increased risk of death or complications in women even after adjusting for such dissimilarities in heart failure variables. ${ }^{31-14}$

An interaction between sex and age group has also been described that suggests that the effect of sex on coronary artery disease prognosis may be different according to the age group analysed. ${ }^{714-17}$

On the other hand, few studies have investigated long term mortality differences between sexes in myocardial infarction with varying results. ${ }^{18-27}$ In general, women have worse prognosis when follow up is less than one year. ${ }^{2}$

This study was aimed at analysing whether the risk of death within 28 days after a myocardial infarction, and during the following three years in 28 day survivors, is higher in women than men and, if so, to assess the role of age, comorbidity and severity of myocardial infarction in this excess of risk.

\section{Methods}

Since 1978, REGICOR (REgistre GIroni del $C O R$; Gerona Heart Registry) has been registering all first myocardial infarction patients arriving alive at the only reference hospital in Gerona with a coronary care unit ${ }^{27} 28$ where most of the myocardial infarction patients in this area are admitted. There are also six community hospitals that refer $70 \%$ of these patients to the reference hospital after emergency treatment. This setting provides the population-based registry of hospitalised myocardial infarction patients in a north eastern region of Spain that covers $591060 \mathrm{~km}^{2}$ and has 509628 inhabitants according to the 1996 census.

\section{PATIENTS}

All patients aged 25 to 74 years, residents in Gerona and admitted to the reference hospital between 1978 and 1997 with a definite diagnosis of first $Q$ wave myocardial infarction, were included in the study. Diagnosis of $\mathrm{Q}$ wave myocardial infarction was based on a definite electrocardiogram - that is, new Q or QS waves - and at least one of the following: increased AMI enzymes (at least twice the upper normal value) and typical pain - that is, located in the anterior chest wall-lasting 20 minutes or more and for which no cause other than coronary heart disease was found.

VARIABLES MEASURED

The following data were prospectively collected: age, sex, smoking status, hypertension and diabetes, history of angina and electrocardiographic myocardial infarction location. Disease severity was established by the clinical 
degree of ventricular dysfunction (acute pulmonary oedema or cardiogenic shock) and the presence of ventricular arrhythmias (fibrillation or tachycardia) requiring immediate treatment. Management variables including thrombolysis, antiplatelet drugs, coronary angiogram, percutaneous transluminal coronary angioplasty and coronary artery bypass surgery were also recorded.

FOLLOW UP

Vital status at 28 days was verified in patients admitted between 1978 and 1997 ( $n=2606)$. Long term follow up of patients admitted between 1978 and 1993 who survived the first 28 days $(n=1790)$ was completed in 1996 by personal or telephone contact and by linkage with the Catalonia Mortality Registry, which collects all death certificates. Thus, patients were followed up for a minimum of three years or until a fatal event occurred.

END POINTS

All cause 28 day mortality was considered as the end point to analyse short-term mortality. To analyse three year mortality, all cause mortality was considered as the end point, although the cause of death was recorded.

STATISTICAL ANALYSIS

Differences between men and women and between deceased and surviving patients were assessed by $\chi^{2}$ test for categorical variables and by Student's $t$ test for continuous variables.

The adjusted odds ratios (OR) of 28 day mortality for women were estimated by a logistic model and the adjusted OR of three year mortality in 28 day survivors for women were estimated using a Cox model. Demographic, comorbidity, clinical and severity variables that showed at least marginally significant differences $(p \leqslant 0.15)$ in bivariate analysis between men and women and between survivors and non-survivors at 28 days or three years and those important variables based on clinical judgement were included as potential confounders. Severity variables (that is, acute pulmonary oedema or cardiogenic shock) that may be interpreted as intermediate mechanisms of death were also included in separated models along with the former variables.

All possible two way biologically plausible interactions were tested in a model that included all main variable effects.

Survival curves were estimated with the Kaplan-Meier method and compared by Mantel-Cox statistics. Calculations were made with the SPSS statistical package.

\section{Results}

Between 1978 and 1997, 2159 men and 447 women aged 25 to 74 admitted consecutively with a first $Q$ wave myocardial infarction were registered. Overall mean age was 59.9 (SD 9.8).

\section{DAY FOLLOW UP}

Among the 2606 patients admitted between 1978 and 1997, $284(10.9 \%)$ died in the first 28 days. Only two cases died from noncardiovascular causes. Within the same period, women presented greater mortality and more frequent severe clinical heart failure than men (table 1). Compared with men, women were older, had more comorbidity (hypertension, diabetes), a greater proportion had an anterior myocardial infarction, there were fewer smokers and they received less thrombolysis. Antiplatelet therapy, coronary angiograms and revascularisation procedures were used similarly in men and women in the first 28 days (table 1).

Older age, female gender, history of hypertension, diabetes, non-smoking status, presence of severe arrhythmias or severe clinical heart failure during the acute phase, anterior myocardial infarction and non-use of thrombolysis and antiplatelet drugs were associated with greater 28 day mortality (table 1 ).

Crude OR of dying within 28 days was 2.27 (95\% confidence intervals: $1.72,2.99)$ in women. In a fully adjusted model, an interaction between sex and age was found. Mortality risk increased with age but was not linear. Therefore, a cut off at 65 years was established

Table 1 Characteristics of 2606 patients with first acute myocardial infarction in Gerona, Spain (1978-1997) by sex and vital status at day 28

\begin{tabular}{|c|c|c|c|c|c|c|}
\hline & \multicolumn{3}{|c|}{ Sex differences } & \multicolumn{3}{|c|}{28 day survival differences } \\
\hline & $\begin{array}{l}\text { Men } \\
(n=2159)\end{array}$ & $\begin{array}{l}\text { Women } \\
(n=447)\end{array}$ & $p$ & $\begin{array}{l}\text { Deceased } \\
(n=284)\end{array}$ & $\begin{array}{l}\text { Survivors } \\
(n=2322)\end{array}$ & $p$ \\
\hline Age:mean (SD) & $59.4(10.1)$ & $65.0(8.2)$ & $<0.001$ & $65.4(7.7)$ & $59.7(10.1)$ & $<0.001$ \\
\hline Sex (\% women) & - & - & - & 29.6 & 15.6 & $<0.001$ \\
\hline Hypertension (\%) & 40.3 & 61.2 & $<0.001$ & 54.2 & 42.7 & $<0.001$ \\
\hline Diabetes $(\%)$ & 18.4 & 45.9 & $<0.001$ & 30.3 & 22.3 & 0.04 \\
\hline Current smokers (\%) & 66.2 & 7.5 & $<0.001$ & 41.6 & 58.4 & $<0.001$ \\
\hline Angina (\%) & 46.8 & 51.3 & 0.09 & 50.2 & 47.2 & 0.48 \\
\hline History of cardiac failure $(\%) \dagger$ & 8.0 & 19.4 & $<0.001$ & 27.0 & 8.4 & $<0.001$ \\
\hline \multicolumn{7}{|c|}{ Clinical characteristics of acute event and interventions } \\
\hline Anterior myocardial infarction (\%) & 45.8 & 53.0 & 0.008 & 65.2 & 44.9 & $<0.001$ \\
\hline APE/cardiogenic shock (\%) & 10.8 & 25.4 & $<0.001$ & 61.8 & 7.5 & $<0.001$ \\
\hline Severe arrhythmia $(\%)^{\star}$ & 15.3 & 14.4 & 0.69 & 36.3 & 12.5 & $<0.001$ \\
\hline Thrombolysis (\%)‡ & 42.2 & 23.9 & $<0.001$ & 15.9 & 41.1 & $<0.001$ \\
\hline Antiplatelet drugs $(\%) \ddagger$ & 86.9 & 85.8 & 0.39 & 66.9 & 88.6 & $<0.001$ \\
\hline 28 day coronary angiograms $(\%)$ & 6.6 & 7.2 & 0.70 & 3.5 & 7.1 & 0.03 \\
\hline 28 day revascularisation $(\%) \rrbracket$ & 2.1 & 2.7 & 0.54 & 2.7 & 2.1 & 0.7 \\
\hline 28 day mortality (\%) & 9.3 & 18.8 & $<0.001$ & - & - & - \\
\hline
\end{tabular}

$\mathrm{APE}=$ acute pulmonary oedema. ${ }^{\star}$ Ventricular fibrillation or tachycardia requiring immediate medical intervention. + Only 1988-1997. In patients admitted from 1988 to 1997 after introduction of routine antiplatelet drugs and thrombolysis. $\$$ Percutaneous transluminal coronary angioplasty or coronary artery bypass surgery. 
Table 2 Characteristics of men and women with first acute myocardial infarction by age group

\begin{tabular}{|c|c|c|c|c|c|c|}
\hline & \multicolumn{3}{|c|}{$<65 y(n=1561)$} & \multicolumn{3}{|c|}{$65-74 y(n=1045)$} \\
\hline & $\begin{array}{l}\text { Men } \\
(n=1386)\end{array}$ & $\begin{array}{l}\text { Women } \\
(n=175)\end{array}$ & $p$ & $\begin{array}{l}\text { Men } \\
(n=773)\end{array}$ & $\begin{array}{l}\text { Women } \\
(n=272)\end{array}$ & $p$ \\
\hline Hypertension (\%) & 37.7 & 52.9 & $<0.001$ & 44.9 & 66.4 & $<0.001$ \\
\hline Diabetes $(\%)$ & 16.1 & 43.0 & $<0.001$ & 22.6 & 47.8 & $<0.001$ \\
\hline Current smokers (\%) & 74.6 & 14.0 & $<0.001$ & 50.9 & 3.4 & $<0.001$ \\
\hline Angina $(\%)$ & 45.8 & 51.5 & 0.2 & 48.4 & 51.1 & 0.49 \\
\hline History of cardiac failure $(\%) \dagger$ & 6.1 & 14.0 & 0.01 & 10.9 & 22.5 & $<0.001$ \\
\hline \multicolumn{7}{|c|}{ Clinical characteristics of acute event and interventions } \\
\hline Anterior myocardial infarction (\%) & 43.2 & 57.0 & 0.001 & 50.6 & 50.4 & 1 \\
\hline $\mathrm{APE} /$ cardiogenic shock (\%) & 8.7 & 16.0 & 0.03 & 14.8 & 33.3 & $<0.001$ \\
\hline Severe arrhythmia (\%) & 15.6 & 9.8 & 0.06 & 14.8 & 17.5 & 0.34 \\
\hline Thrombolysis $(\%) \ddagger$ & 46.6 & 31.2 & 0.007 & 35.3 & 19.8 & $<0.001$ \\
\hline Antiplatelet drugs $(\%) \ddagger$ & 88.4 & 93.5 & 0.2 & 84.7 & 81.5 & 0.4 \\
\hline 28 day coronary angiograms (\%) & 5.0 & 5.7 & 0.81 & 9.4 & 8.1 & 0.62 \\
\hline 28 day revascularisation $(\%) \int$ & 1.4 & 1.3 & 1 & 3.4 & 3.7 & 1 \\
\hline 28 day mortality (\%) & 6.9 & 6.9 & 0.91 & 13.6 & 26.5 & $<0.001$ \\
\hline
\end{tabular}

$\mathrm{APE}=$ acute pulmonary oedema. ${ }^{\star}$ Ventricular fibrillation or tachycardia requiring immediate medical intervention. †Only 1988-1997. $¥$ In patients admitted from 1988 to 1997 after introduction of routine antiplatelet drugs and thrombolysis. \$Percutaneous transluminal coronary angioplasty or coronary artery bypass surgery.

that defined two groups according to, on the one hand, statistical and, on the other, demographic criteria.

Unadjusted 28 day case fatality in patients under 65 was similar in men and women $(6.9 \%$ and $6.9 \%$, respectively). In women aged 65 to 74 , case fatality was twice that of men $(26.5 \%$ and $13.6 \%$, respectively). Differences in comorbidity and clinical characteristics in each age stratum between men and women are shown in table 2 .

Adjusted logistic regression models showed opposing results in patients over and under 65 (fig 1): women aged 65 to 74 years had a higher risk of dying within 28 days than men of the same age, but women younger than 65 had lower mortality risk than their male counterparts. These findings were consistently significant regardless of the adjustment for confounding factors (model 1, fig 1) and even if we add the severity of myocardial infarction (pulmonary oedema, cardiogenic shock) to the model 1 (model 2, fig 1).

THREE YEAR FOLLOW UP

Overall three year survival curves, (that is, including first 28 days) are presented by sex and age group in figure 2 for the 2053 patients admitted from 1978 to 1993 . Altogether 263 of these patients died within 28 days after onset of myocardial infarction symptoms. Differences between age and gender groups in survival curves were mainly attributable to differences in early mortality (28 days).

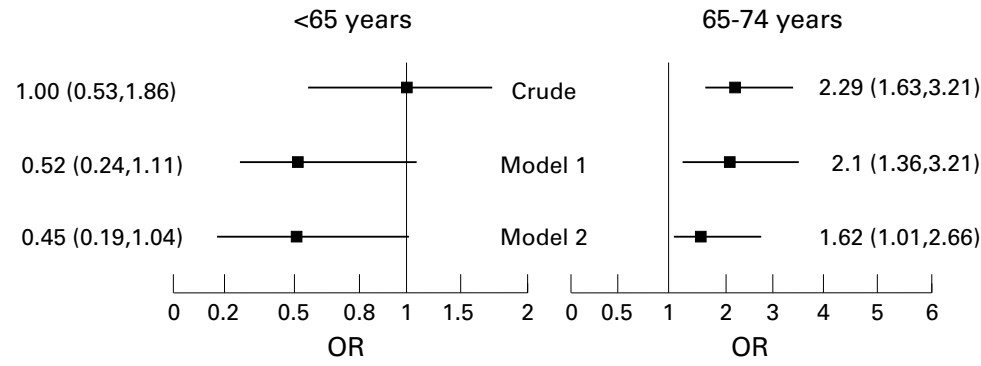

Figure 1 Adjusted odds ratio and 95\% confidence intervals of 28 day mortality for women after a first myocardial infarction by age group (over and under 65). Model 1 adjusted for smoking, anterior location of myocardial infarction, diabetes, hypertension, and thrombolysis. Model 2 as model 1 plus acute pulmonary oedema or cardiogenic shock. Further adjustment for age (as a continuous variable) or period of inclusion did not significantly change the odds ratio in any model.
Only 10 patients $(0.5 \%)$ were lost to the three year follow up among the 179028 day survivors of the 1978-1993 cohort. Among these 28 day survivors, three year mortality was $12.0 \%$ and women showed worse total three year mortality than men $(21.8 \%$ versus $10.3 \%$, $\mathrm{p}<0.0001)$. Causes of death during long term follow up were coronary in $73.7 \%$ of men and $83.1 \%$ of women, other cardiac $3.8 \%$ and $5.1 \%$, cerebrovascular $2.6 \%$ and $1.7 \%$ and other causes $16.4 \%$ and $10.2 \%$, respectively.

Twenty eight day survivors' characteristics related to three year total mortality are shown in table 3. Baseline differences between sexes in 28 day survivors were very similar to those observed for the whole cohort and, during the first three years of follow up, women and men presented similar non-fatal Q wave reinfarction rates and showed no significant differences in the use rates of coronary angiograms and revascularisation procedure (table 3 ).

Crude risk of three year total mortality for 28 day survivors was higher in women than men $(\mathrm{OR}=2.3,95 \%$ confidence intervals: $1.7,3.1$ ). Adjustment for confounding variables (that is, age, smoking, diabetes, hypertension, thrombolysis, and acute pulmonary oedema or cardiogenic shock during the acute phase) led to non-statistically significant $\mathrm{OR}$ for gender $(\mathrm{OR}=1.3,95 \%$ confidence intervals: $0.9,1.9)$. No interaction was found to be statistically significant.

\section{Discussion}

This study shows that women aged 65 to 74 have more than twofold the risk of 28 day mortality after a first $\mathrm{Q}$ wave myocardial infarction than men, regardless of any clinical or severity characteristic. In contrast, female patients younger than 65 showed similar crude risk of dying compared with men of the same age group, and there were no statistically significant differences between sexes after adjustment for potential confounders. No independent sex effect on three year mortality risk was observed in 28 day survivors.

Though crude early mortality is higher in hospitalised women than in men in most studies, adjusted results differ. ${ }^{2929}$ Comparability of adjusted results is difficult because of the 


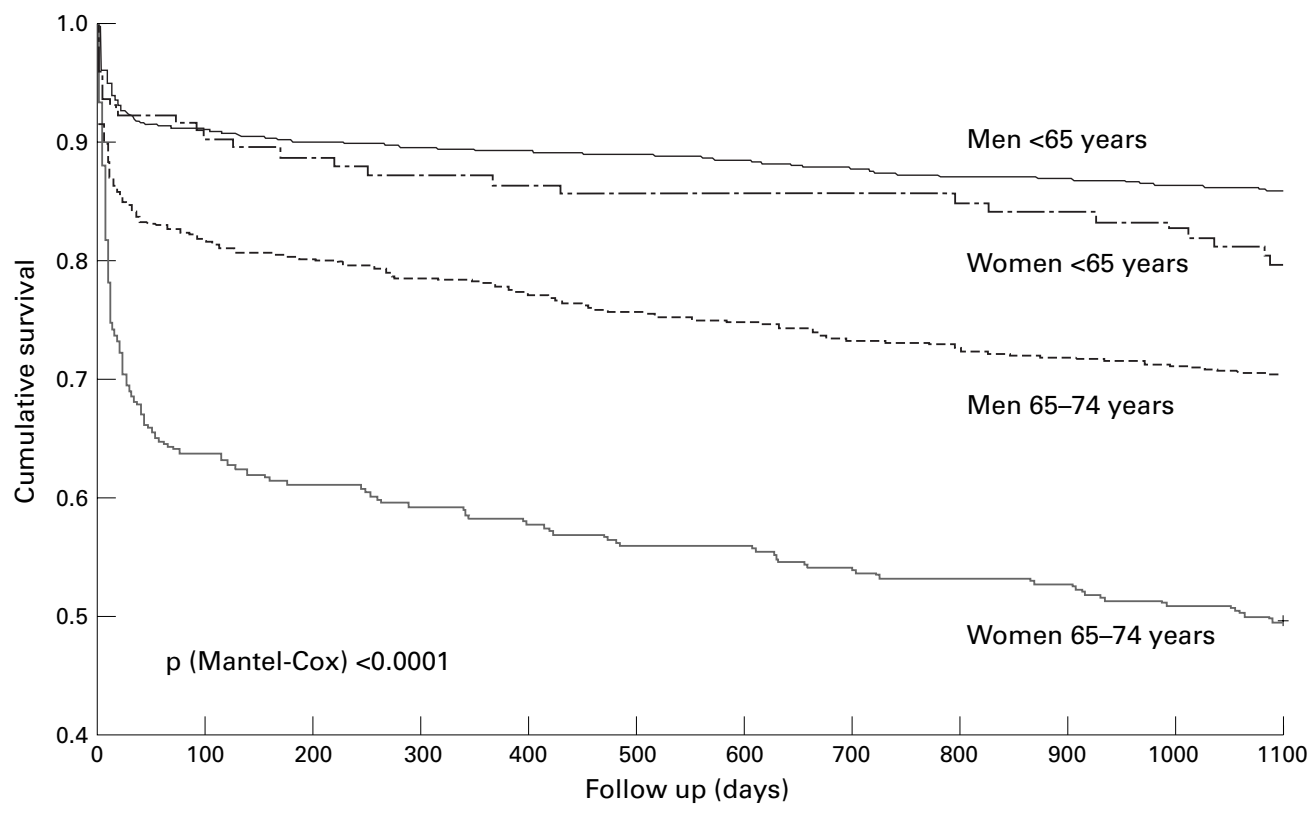

Figure 2 Survival curves by sex and age group in 2053 patients (351 women and 1702 men) with a first myocardial infarction in Gerona, Spain 1978-1993.

great heterogeneity in methodology, either in study design, inclusion criteria of the patients or in controlling for confounding factors. ${ }^{29} 30$

Age has been recognised to be a major independent risk factor of mortality after myocardial infarction. ${ }^{29}$ In many studies the excess risk in women disappeared after adjusting for differences in age distribution or other confounding variables. ${ }^{29}$ In our study, a differential risk in women was observed according to age strata (younger and older than 65), even after adjusting for other potentially confounding variables (fig 1). Few works have suggested a diverging effect of female sex on myocardial infarction survival in different age groups. ${ }^{74-17}$ All found a significant interaction between age and sex, but in the opposite direction to ours. However, it is difficult to compare our results because of considerable differences in the study designs: studies differed in age range; some included patients enrolled in clinical trials (non-consecutive), ${ }^{77}$ or only patients admitted to coronary units ${ }^{17}$ and some included a large proportion of patients with non- $Q$ wave myocardial infarction or with previous history of myocardial infarction. ${ }^{71415}$ Particularly striking are the differences between our results and those from Vaccarino in her large cohort study of more than 380000 patients after excluding $21 \%$ of candidates because of transfer to another hospital. ${ }^{16}$ This may have introduced a selection bias because it is probable that transferred patients were more severely diseased. In fact, the mortality observed could be considered low taking into account that patients up to 89 years of age were included. Furthermore, no information is provided as to which proportion of races are

Table 3 Baseline patient demographic, clinical and management characteristics associated with three year total mortality in 28 day survivors

\begin{tabular}{|c|c|c|c|c|c|c|}
\hline & \multicolumn{3}{|c|}{ Sex differences } & \multicolumn{3}{|c|}{ Three year survival differences } \\
\hline & $\begin{array}{l}\text { Men } \\
(n=1519)\end{array}$ & $\begin{array}{l}\text { Women } \\
(n=271)\end{array}$ & $p$ & $\begin{array}{l}\text { Deceased } \\
(n=215)\end{array}$ & $\begin{array}{l}\text { Survivors } \\
(n=1575)\end{array}$ & $p$ \\
\hline Age:mean (SD) & $58.9(10.1)$ & $64.0(8.1)$ & $<0.001$ & $65.4(7.7)$ & $59.7(10.1)$ & $<0.001$ \\
\hline Sex (\% women) & - & - & - & 27.4 & 13.5 & $<0.001$ \\
\hline Hypertension (\%) & 39.0 & 59.1 & $<0.001$ & 50.5 & 41.1 & 0.01 \\
\hline Diabetes $(\%)$ & 16.7 & 48.0 & $<0.001$ & 30.2 & 20.4 & 0.001 \\
\hline Current smokers (\%) & 68.9 & 7.8 & $<0.001$ & 46.2 & 61.6 & $<0.001$ \\
\hline Angina $(\%)$ & 46.7 & 51.7 & 0.15 & 52.4 & 46.8 & 0.15 \\
\hline History of cardiac failure $(\%) \dagger$ & 7.1 & 14.9 & 0.008 & 18.4 & 7.2 & 0.002 \\
\hline \multicolumn{7}{|l|}{ Clinical characteristics of acute event and interventions } \\
\hline Anterior myocardial infarction $(\%)$ & 44.1 & 53.5 & 0.005 & 48.1 & 45.2 & 0.48 \\
\hline $\mathrm{APE} /$ cardiogenic shock (\%) & 5.4 & 15.8 & $<0.001$ & 19.2 & 5.3 & $<0.001$ \\
\hline Severe arrhythmia $(\%)^{\star}$ & 10.8 & 9.8 & 0.7 & 15.0 & 10.0 & 0.03 \\
\hline Thrombolysis (\%) $\ddagger$ & 37.2 & 14.9 & $<0.001$ & 17.7 & 35.4 & 0.002 \\
\hline Antiplatelet drugs (\%)‡ & 81.6 & 85.1 & 0.43 & 75.9 & 82.8 & 0.17 \\
\hline 28 day coronary angiograms $(\%)$ & 4.1 & 5.5 & 0.4 & 3.8 & 4.5 & 0.78 \\
\hline 28 day revascularisation $(\%) \int$ & 1.1 & 1.8 & 0.5 & 1.0 & 1.3 & 1 \\
\hline \multicolumn{7}{|c|}{ Events during three year follow up (after day 28) } \\
\hline Three year mortality (\%) & 21.8 & 10.3 & $<0.001$ & - & - & - \\
\hline Three year coronary angiograms (\%) & 13.6 & 12.8 & 0.8 & 9.2 & 14.0 & 0.09 \\
\hline Three year revascularisation $(\%) \int$ & 7.0 & 7.9 & 0.74 & 5.5 & 7.4 & 0.42 \\
\hline Three year non-fatal $Q$ wave reinfarction (\%) & 5.1 & 4.2 & 0.63 & 6.1 & 4.8 & 0.50 \\
\hline
\end{tabular}

$\mathrm{APE}=$ acute pulmonary oedema during acute phase. ${ }^{\star}$ Ventricular fibrillation or tachycardia requiring immediate medical intervention during acute phase. †Only after 1988. $¥$ In patients admitted after introduction of routine antiplatelet drugs and thrombolysis (1988). @Percutaneous transluminal coronary angioplasty or coronary bypass surgery. 
present in the cohort, which may be important according to recent findings suggesting that black patients were less likely to receive lifesaving treatment. ${ }^{31}$ The low mortality observed in Vaccarino's cohort may also be related to the high proportion of non-Q wave AMI (50\%), which is known to have lower early mortality, and they were excluded in our study. Non-Q wave myocardial infarction cases may range $7 \%$ to $50 \%$ in several published studies. ${ }^{16}{ }^{32}$

Moreover, these studies were conducted in countries with a high incidence of myocardial infarction. ${ }^{74-17}$ Other studies have described a strong inverse correlation between population event rate and female/male case-fatality ratio. ${ }^{33}$ Thus, southern European countries are an example of this phenomenon: low myocardial infarction incidence rates are observed together with high female:male case fatality ratios.

Myocardial infarction incidence among Spanish women is approximately one fifth that of the USA, which leads to a low number of female cases below 65 years in our region and around one third in men. All these factors may play a part in the fact that we found lower mortality in women younger than 65 years, in discrepancy with other authors. Interestingly, myocardial infarction case-fatality is also lower in both sexes in Spain. ${ }^{34}$ In this respect, we might hypothesise that young women develop AMI not only with less frequency but also with less severe characteristics in southern Europe than in the USA. This idea is in accordance with lower absolute risk associated to particular risk factor values found in southern Europe by other authors in this region. ${ }^{35}{ }^{36}$ Maybe the necessity of longer exposure to risk factors exists in this area to develop coronary heart disease.

To assess whether worse prognosis in women is related to greater severity of myocardial infarction (pulmonary oedema, cardiogenic shock), adjustment for these mechanisms of death, even if they fail to meet confounding criteria, would be useful. ${ }^{8}$ Some studies reflect a worse prognosis in hospitalised women after adjusting for heart failure and other dissimilarities between sexes, ${ }^{31-14}$ others do not find these differences after adjustment. ${ }^{815}$

In this study, women had more frequent severe heart failure during the acute phase than men for both age groups. However, the adjusted decreased mortality risk in women under 65 and the increased risk in women aged 65 to 74 were not modified by the inclusion of variables that measured heart failure during the acute phase (fig 1, model 1 and 2 respectively). This suggests that some unknown factor would contribute to the different prognosis in women before and after 65 years independently of the development of heart failure. Given that differences in heart failure between men and women do not seem to explain the early mortality risk differences, alternative possibilities should be sought.

In relation to other factors influencing mortality, some studies reflected gender differences either in the efficacy of medications used to treat myocardial infarction (particularly, thrombolysis, $\beta$ blockers and aspirin) or in the
KEY POINTS

- Mortality risk in men and women hospitalised after a myocardial infarction differ according to age.

- Women aged 65-74 had higher early mortality risk than men of the same age after adjusting for age, comorbidity and acute complications including heart failure. Conversely, women under 65 tended to be at lower risk of early mortality than men.

- Three year mortality of 28 day survivors did not differ between sexes.

use of effective treatments. ${ }^{29}$ Moreover, some studies suggest a gender gap in the likelihood of women receiving less acute cardiovascular diagnostic procedures (coronary angiogram) or interventions (revascularisation procedures). ${ }^{37}{ }^{38}$ In our study, as in others, ${ }^{39}$ invasive procedures and aspirin treatment did not differ between sexes. Women received less thrombolysis, which was probably related to longer delay in reaching hospital (4.7 hours in women and 2.3 hours in men, $\mathrm{p}=0.02$, data not shown, period 1992-94). However, the results held after adjusting for this treatment.

The high prevalence of diabetes in our population of myocardial infarction patients, particularly in women, is similar to that found in other Spanish registries. ${ }^{80}$

THREE YEAR MORTALITY OF FIRST MYOCARDIAL INFARCTION SURVIVORS

As in short-term mortality, there is great heterogeneity in the methodology across the different studies that assess long term prognosis after a myocardial infarction. ${ }^{30}$

Higher risk of death in women, even after adjustment for age and comorbidity, was observed in studies analysing periods of one year or less. ${ }^{38}$ Conversely, those analysing longer periods observed no differences, ${ }^{6}{ }^{18-22} 34$ increased risk in women ${ }^{26}$ or a statistically significant benefit in women. ${ }^{23-25}$ In our study, no statistically significant differences were found between sexes in three year 28 day survivors' mortality when adjusting for all confounding variables.

STUDY CHARACTERISTICS AND CLINICAL IMPLICATIONS

For patients older and younger than 65, the need for age adjustment could also be postulated as age, even within each of the two age subgroups, may continue to influence early mortality. Over the long inclusion period of this study (1978 to 1997), a decreasing mortality risk was reported, although no differences in gender distribution were observed among time periods. ${ }^{28}$ Adjustment for the period of inclusion and age within each age group yielded ORs for sex that did not change significantly in any model (results not shown).

Considering previous heart failure-which is more frequent among women - in the multivariate analysis implies excluding 1194 cases admitted before 1988 because of the lack of 
information on this variable before that year, but yielded similar results to those presented with no modification of the risk estimates for sex.

In our study, only first $\mathrm{Q}$ wave definite myocardial infarction patients aged 25-74 years admitted to a reference hospital were included. The use of some restrictive criteria, such as upper age limit at 74 years and first myocardial infarction, may help to improve the accuracy of excess risk estimates and prevent complex model adjustment (that is, time since last event, number of previous events, or left ventricular ejection fraction after these events). Moreover, patients are homogeneous in diagnostic criteria as we excluded non-Q wave myocardial infarction cases that may range 6.6 to $42.6 \%$ in several published studies. ${ }^{32}$ In our study non-Q wave myocardial infarction represents a $16.7 \%$ of total myocardial infarction admitted after 1990 .

It is possible that case fatality differences during hospitalisation according to age and sex were attributable to sex and age differences in the mortality before hospitalisation. According to 1990-97 data of our REGICOR population MI registry, overall 28 day case fatality in women was significantly higher than in men $(47.2 \%$ versus $39.6 \%, p=0.005)$. Furthermore, we did not find any substantial differences between the proportion of prehospital deaths between men and women in each age strata (proportion of prehospital deaths: $69.5 \%$ and $71.3 \%$ in men and women under 65 respectively, and $61.8 \%$ and $59.8 \%$ in men and women of 65 and older). From a public health point of view, the large prehospital case fatality is a major issue. None the less, the health care system is concerned with the fate of AMI patients who reach hospitals alive, as clinicians need to orientate their efforts towards reducing inhospital case fatality. In our study only patients admitted in a tertiary hospital are included and the results are adjusted for the possible confounding factors (that is, age, comorbidity, severity) that would be difficult in prehospital deaths because of the large proportion of missing comorbidity data.

Our data support the idea that the higher 28 day mortality in women with $\mathrm{Q}$ wave myocardial infarction is mainly attributable to the large number of patients aged 65 to 74 years in whom the risk is at least twice that in men. This difference is not explained by the greater frequency of severe heart failure after myocardial infarction. Young women with myocardial infarction do not seem to be a special group of risk. In 28 day survivors, total mortality at three years is similar in both sexes. Persons and institutions colaborating in REGICOR: X Albert,
(Clinica Girona); M Saguer, M Vicente, F Monzón (Hospital
Comarcal de Figueres); J Bisbe, P Cortés, A Agustí, M Barcons
(Hospital Comarcal Sant Jaume d'Olot); N Constans, R Massa
(Hospital Comarcal de La Selva); F Bassó, A Masabeu, J Inoriza
(Hospital Comarcal de Palamós); C Martinez, (Servei
d'Emergencies Mèdiques); J C Guerra (Hospital Provincial de
Santa Caterina, Gerona); X Albert, R Masiá, J Sala (Hospital
Universitari Dr Josep Trueta, Gerona); C Aubó, M Bosch, M
Cardona, M I Covas, R Elosua, M Gil, J Marrugat, S Martín, A
Pena, G Pérez, P Roset, M Sentí M (Institut Municipal
d'Investigació Mèdica, Barcelona). We appreciate the English
revision of the manuscript made by Christine O'Hara.

Funding: this project was supported by grants FIS-90/0672 and FIS-93/0568 from the Fondo de Investigación Sanitaria and received partial support through grant CIRIT/1999 SGR 00423 of the Generalitat de Catalunya.

Conflicts of interest: none.

1 Mosca L, Manson JE, Sutherland S, et al. Cardiovascular disease in women. A statement for healthcare professionals from the American Heart Association. Dallas: Scientific statement of the American Heart Association, 1997.

2 Vaccarino V, Krumholz HM, Berkman LF, et al. Sex differences in mortality after myocardial infarction. Is there evidence for an increased risk for women?. Circulation 19nce for an incr:

3 Greenland P, Reicher-Reiss H, Goldbourt U, et al. In-hospital and 1-year mortality in 1,524 women after myocardial infarction. Comparison with 4,315 men. Circulation 1991;83:484-91.

4 Becker RC, Terrin M, Ross R, et al. Comparison of clinical outcomes for men and women after acute myocardial infarction. Ann Intern Med 1994;120:638-45.

5 Jenkins JS, Flaker GC, Nolte B, et al. Causes of higher in-hospital mortality in women than in men after acute myocardial infarction: the Framingham study. Am f Cardiol 1994;73:319-22.

6 Marrugat J, Antó JM, Sala J, et al for the REGICOR investigators. Influence of gender in acute and long-term cardiac
mortality after a first myocardial infarction. $\mathcal{F}$ Clin Epidemiol 1994;47:111-18.

7 Demirovic J, Blackburn H, McGovern PG, et al. Sex differences in early mortality after acute myocardial infarction ences in early mortality after acute myocardial infarction
(The Minnesota Heart Survey). Am 7 Cardiol 1995;75: 1096-101.

8 Marrugat J, Sala J, Masiá R, et al for the RESCATE investigators. Mortality differences between men and women follow ing first myocardial infarction. $\mathcal{F} A M A$ 1998;280:1405-9.

9 Marrugat J, Gil M, Sala J. Sex differences in survival rates after acute myocardial infarction. F Cardiovasc Risk 1999;6: 89-97.

10 Sonke GS, Beaglehole R, Steward AW, et al. Sex differences in case fatality and after admission to hospital after acute cardiac events: analysis of community-based coronary heart disease register. $B M F$ 1996;313:853-5.

11 Malacrida R, Genoni M, Maggioni AP, et al for the Third International Study of Infarct Survival Collaborative Group. A comparison of the early outcome of acute myocardial infarction in women and men. $N$ Engl $\mathcal{F} \mathrm{Med}$ 1998;338:8-13.

12 Weaver WD, White HD, Wilcox RG, et al. Comparisons of characteristics and outcomes among women and men with acute myocardial infarction treated with thrombolytic

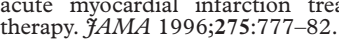

13 Kober L, Torp-Pedersen C, Ottesen M, et al on behalf of the TRACE Study Group. Influence of gender on short- and long-term mortality after acute myocardial infarction. Am $\mathcal{F}$
Cardiol 1996;77:1052-6.

14 He J, Klag MJ, Whelthon PK, et al. Short- and long-term prognosis after acute myocardial infarction in Chinese men and women. Am $\mathcal{F}$ Epidemiol 1994;139:693-703.

15 Vaccarino V, Horwitz R, Meehan T, et al. Sex differences in mortality after myocardial infarction. Arch Intern Med 1998;158:2054-62.

16 Vaccarino V, Parsons L, Every N, et al for the National registry of myocardial infarction. Sex based differences in early mortality after myocardial infarction. $N$ Engl $f \mathrm{Med}$ mortality after myo

17 Galatius-Jensen S, Launbjerg J, Spange Mortensen LS, et al. Sex-related differences in short and long-term prognosis after acute myocardial infarction: 10-year follow-up of 3,073 patients in database of first Danish verapamil infarc3,073 patients in database of first
tion trial. $B M \mathcal{F} 1996 ; 313: 137-40$.

18 Fiebach NH, Viscoli CM, Horwitz RI. Differences between women and men in survival after myocardial infarction. Biology or methodology?. fAMA 1990;263:1092-6.

19 Maynard C, Every NR, Martin JS, et al. Association of gender and survival in patients with acute myocardial infarction. Arch Intern Med 1997;157:1379-84.

20 Brett KM, Madans JH. Long-term survival after coronary heart disease. Comparisons between men and women in a national sample. Ann Epidemiol 1995;5:25-32.

21 Gottlieb S, Moss A, McDermott M, et al. Comparison of posthospital survival after acute myocardial infarction in women and men. Am f Cardiol 1994;74:727-30.

22 Kostis J, Wilson A, O'Dowd K, et al for the MIDAS study group. Sex differences in the management and long-term group. Sex differences in the management and long-term
outcome of acute myocardial infarction. Circulation 1994; outcome of acut
$\mathbf{9 0} 1715-29$.

23 Wong DN, Cupples LA, Ostfeld AM, et al. Risk factors for long-term coronary prognosis after initial myocardial infarction: the Framingham Study. Am $f$ Epidemiol 1989;130:469-80.

24 Martin CA, Thompson PL, Armstrong BK, et al. Longterm prognosis after recovery from myocardial infarction: a nine-year follow-up of the Perth Coronary Register. Circulation 1983;68:961-9.

25 Pohjola S, Siltanen P, Romo M. Five-year survival of 728 patients after myocardial infarction: a community study. $\mathrm{Br}$ Heart $\mathcal{F} 1980 ; 43: 176-83$.

26 Benderly M, Behar S, Reicher-Reiss H, et al for the SPRINT Investigators. Long-term prognosis of women after myocardial infarction. Am $\mathcal{F}$ Epidemiol 1997;146:153-60.

27 Sala J, Marrugat, Masiá R, et al for the REGICOR investigators. Improvement in survival after myocardial inf-
arction between $1978-85$ and $1986-88$ in the REGICOR study. Eur Heart $\mathcal{F}$ 1995;16:779-84. 
28 Gil M, Marrugat J, Sala J, et al for the REGICOR investigators. Relationship of therapeutic improvements and 28-day
case fatality in patients hospitalized with acute myocardial case fatality in patients hospitalized with acute myocardial
infarction between 1978 and 1993 in the REGICOR study, infarction between 1978 and 1993 in the REG

29 Nohria A, Vaccarino V, Krumholz H. Gender differences in mortality after myocardial infarction. Cardiol Clin 1998;16: 45-57.

30 Marx BE, Feinstein AR. Methodologic sources of inconsistent prognoses for post-acute Myocardial Infarction. $\mathrm{Am} f$ Med 1995;98:537-50.

31 Canto JG, Allison JJ, Kiefe CI, et al. Relation of race and sex to the use of reperfusion therapy in Medicare beneficiaries with acute myocardial infarction. N Engl f Med 2000;342: 1094-100.

32 Gibson RS, Beller GA, Gheorghiade $M$, et al. The prevalence and clinical significance of residual myocardial ischemia 2 weeks after uncomplicated non-Q wave infarction: a prospective clinical study. Circulation 1986;73: infarction:

33 Chambless L, Keil U, Dobson A, et al for the MONICA Project. Population versus clinical view of case fatality from
acute coronary heart disease. Results from the WHO acute coronary heart disease. Results from the WHO 59.

34 Pérez G, Pena A, Sala J, et al for the REGICOR Investigators. Acute myocardial infarction case fatality, incidence and mortality rates in a population registry in the province of Gerona, Spain 1990 to 1992. Int 7 Epidemiol 1998;27:599-604.

35 Kromhout D. On the waves of the Seven Countries Study. Eur Heart F 1999;20: 796-802.

36 Marrugat J, Sentí M. High cholesterol may not have same effect on cardiovascular risk in southern Europe as elsewhere. BMf 2000;320:249.

37 Kudenchuk P, Maynard C, Martin J, et al. Comparison of presentation, treatment and outcome of acute myocardial infarction in men versus women (the Myocardial Infarction Triage and Intervention Registry). Am f Cardiol 1996;78:914.

38 Weitzman S, Cooper L, Chambless L, et al. Gender, racial and geographic differences in the performance of cardiac diagnostic and therapeutic procedures for hospitalized cute myocardial infarction in four states. Am f Cardiol 1997;79:722-6.

39 Tunstall-Pedoe H, Morrison C, Woodward M, et al. Sex differences in myocardial infarction and coronary deaths in the Scottish MONICA population of Glasgow 1985-91: presentation, diagnosis, treatment and 28-day case fatality presentation, diagnosis, treatment and 28-day case fatality of 3,991 .

40 Fiol M, Cabades A, Sala J, et al. Variability in the in-hospital management of acute myocardial infarction in Spain. IBERICA study (Investigación, Busqueda Especifica y Registro de Isquemia Coronaria Aguda). Rev Esp Cardiol 2001;54:443-52.

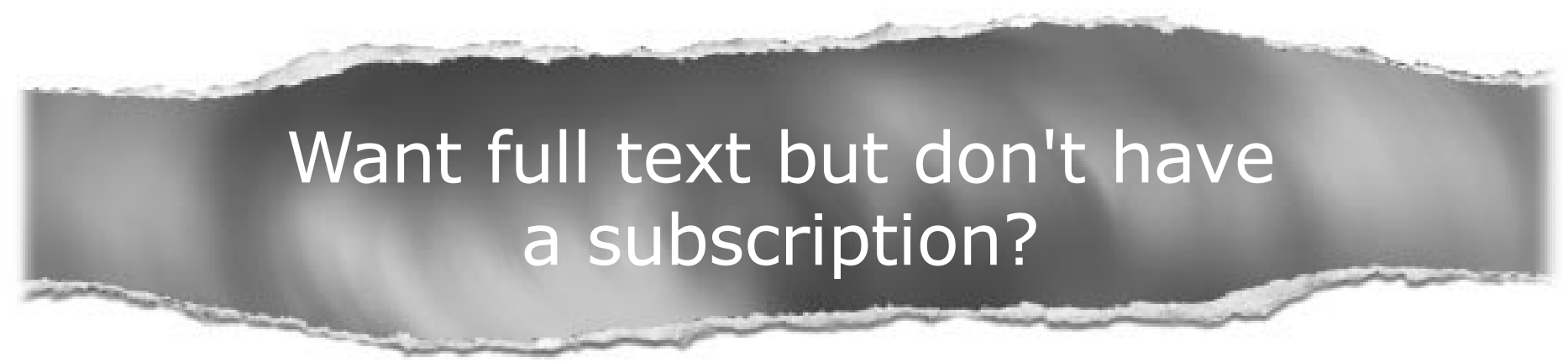

\section{Pay per view}

For just $\$ 8$ you can purchase the full text of individual articles using our secure online ordering service. You will have access to the full text of the relevant article for 48 hours during which time you may

download and print the pdf file for personal use.

www.jech.com 